\title{
Enhanced production of recombinant serratiopeptidase in Escherichia coli and its characterization as a potential biosimilar to native biotherapeutic counterpart
}

Vishal Srivastava, Shivam Mishra and Tapan K. Chaudhuri*

\begin{abstract}
Background: Serratia marcescens, a Gram-negative nosocomial pathogen secretes a 50 kDa multi-domain zinc metalloprotease called serratiopeptidase. Broad substrate specificity of serratiopeptidase makes it suitable for detergent and food processing industries The protein shows potent anti-inflammatory, anti-edemic, analgesic, antibiofilm activity and sold as an individual or fixed-dose enteric-coated tablets combined with other drugs. Although controversial, serratiopeptidase as drug is used in the treatment of chronic sinusitis, carpal tunnel syndrome, sprains, torn ligaments, and postoperative inflammation. Since the native producer of serratiopeptidase is a pathogenic microorganism, the current production methods need to be replaced by alternative approaches. Heterologous expression of serratiopeptidase in E. coli was tried before but not found suitable due to the limited yield, and other expression related issues due to its inherent proteolytic activity such as cytotoxicity, cell death, no expression, minimal expression, or inactive protein accumulation.

Results: Recombinant expression of mature form serratiopeptidase in E. coli seems toxic and resulted in the failure of transformation and other expression related issues. Although E. coli C43(DE3) cells, express protein correctly, the yield was compromised severely. Optimization of protein expression process parameters such as nutrient composition, induction point, inducer concentration, post-induction duration, etc., caused significant enhancement in serratiopeptidase production (57.9 $\pm 0.73 \%$ of total cellular protein). Expressed protein formed insoluble, enzymatically inactive inclusion bodies, and gave 40-45 mg/l homogenous (> 98\% purity) biologically active and conformationally similar serratiopeptidase to the commercial counterpart upon refolding and purification.
\end{abstract}

Conclusion: Expression of mature serratiopeptidase in E. coli C43(DE3) cells eliminated the protein expression associated with toxicity issues. Further optimization of process parameters significantly enhanced the overexpression of protein resulting in the higher yield of pure and functionally active recombinant serratiopeptidase. The biological activity and conformational features of recombinant serratiopeptidase were very similar to the commercially available counterpart suggesting it-a potential biosimilar of therapeutic and industrial relevance.

Keywords: Serratia marcescens, Serratiopeptidase, Escherichia coli, Metalloprotease, Inclusion bodies, Heterologous protein expression, Recombinant mature version serratiopeptidase (rMSrp)

*Correspondence: tkchaudhuri@bioschool.iitd.ac.in;

tapanchaudhuri@hotmail.com

Kusuma School of Biological Sciences, Indian Institute of Technology

Delhi, Hauz Khas, New Delhi 110016, India

\section{Background}

Proteases are one of the most abundant protein family represented by those protein molecules which hydrolyze substrate protein molecules by disruption of the peptide bonds in between constituent amino acids [1]. 
Extracellular microbial proteases are pivotal for the growth and survival of protease producing microrganisms [2] as they do protein catabolism in the surrounding environment producing smaller peptides or amino acids to fulfill the nutritional requirements of source organism [3]. Proteases act as virulence factors and are critical for initiating as well as establishing microbial infections. Apart from carrying out crucial biological functions, proteases are equally relevant in a variety of commercial and industrial applications such as-an additive in detergents, in food processing (meat tenderization, milk coagulation), brewing, leather tanning and paper industry [4-6]. The hydrolytic activity of proteases is equally relevant for therapeutic purposes. They are used as an oral digestive aid, local clearing agents for solubilizing protein deposits, minimizing inflammation, or as a thrombolytic agent in thromboembolic disorders [7]. Food and Drug Administration (FDA) approved at least 12 proteases as a drug for treating disorders like-hemophilia, stroke, AMI (acute myocardial infarction), unwanted inflammatory response, and digestive disorders [8-11]. Such a wide variety of industrial and therapeutic applications account for around $60 \%$ of worldwide enzyme sales attributed alone to proteolytic enzymes [12].

Serratia marcescens, a Gram-negative opportunistic pathogen secretes at least four different types of proteases. The majority of the proteolytic activity exhibited in the extracellular secretion was attributed to a $50 \mathrm{kDa}$ zinc metalloprotease known as serralysin, serrapeptase, or serratiopeptidase [13-15]. Serratiopeptidase shows multidomain architecture containing a zinc atom in its catalytic site located in the N-terminal domain. The $\mathrm{C}$-terminal domain of the protein consists of repeat-in toxin (RTX) glycine-aspartate rich motifs responsible for the binding of seven calcium atoms to the protein [16]. Broad specificity of serratiopeptidase is essential for the protein as a virulence factor to exhibit cytotoxicity and immunomodulation in a variety of hosts [17-21]. The broad specificity of serratiopeptidase is equally important for industrial applications such as - a detergent additive, in food processing, brewing, leather, and paper industry $[22,23]$. Serratiopeptidase shows the potent anti-inflammatory and analgesic activity of therapeutic relevance and sold in the market either as a single component or as fixed-dose combination (FDC) enteric-coated tablets. The drug is prescribed for treating disorders likechronic sinusitis, post-traumatic swelling, fibrocystic breast disease, bronchitis, healing after molar extraction, and post-surgical inflammation in several Asian and European countries [24]. The anti-inflammatory action of serratiopeptidase is attributed to its ability to break down insoluble protein exudates, facilitating drainage, and hydrolyzing inflammatory protein molecules [25]. The analgesic action of serratiopeptidase possibly functions through inhibiting the release of pain-inducing amines [26]. Serratiopeptidase is a potent anti-biofilm molecule and also disrupts amyloid fibrils in vitro as well as in vivo $[27,28]$.

The industrial and pharmaceutical demand of serratiopeptidase is fulfilled through growing wild and mutant strains of $S$. marcescens in nutrient-rich growth medium and further extracting the protein out from the extracellular broth. The present approach of production is source organism dependent and provides a narrow scope of optimization, hence also limiting the yield [22]. The pathogenic nature of the source organism and its association with a variety of infection ensures the need for an alternative approach for serratiopeptidase production. Serratia marcescens associated infections include but are not limited to ventilator-associated pneumonia, endocarditis, bacteremia, post-surgical infections, microbial keratitis, urinary tract infection, meningitis and necrotizing fasciitis $[13,17,18,29,30]$. Multi-drug resistant strains of $S$. marcescens are associated with clinical outbreaks in intensive and neonatal care unit are in the high priority list of World health organization (WHO) for developing novel antimicrobial therapies [31,32]. Bulk release of bacterial biomass is a common thing during large-scale production of serratiopeptidase and potentially hazardous for associated people with industrial operations. Recombinant expression of serratiopeptidase in E. coli based system seems to be a viable solution that will not only limit the use of native pathogenic source strain but also provide an opportunity of various expression parameters. Optimization of expression parameters would result in enhancement in yield and even might prove cost-effective.

Escherichia coli cells are well studied, and a variety of engineered expression strains of $E$. coli are available. It also has a considerably fast growth rate and fermentation batch turnaround number equal to 300 per year, which is far higher than any of the host systems available [33]. E. coli are nutritionally versatile and in combination with the above-mentioned properties fit most suitable system for heterologous protein expression. E. coli based expression systems are used for recombinant production of around 30\% FDA approved therapeutically relevant protein molecules; viz-human insulin, plasminogen activator, growth hormone [34]. Even after having such versatility, and Serratia protease genes cloned nearly 30 years ago [35] industries prefer the wild source organisms over $E$. coli based expression. The answer lies in the fact that E. coli based heterologous expression of proteases causes critical cellular stress due to the associated catalytic activity of proteases and failure of the expression system [36]. Sign of failure of expression system is 
often visualized in the form of cell lysis, growth inhibition, instability of the expression plasmids, lack of protein expression, degraded protein expression, or deposition of the proteins into non-functional misfolded aggregates; i.e., inclusion bodies [37].

The present work demonstrates the successful execution of an $E$. coli based alternative method for serratiopeptidase production in its propeptide devoid mature form. The expression was carried out in E. coli BL21 $C 43(D E 3)$ cells designed explicitly for membrane and toxic protein expression. A significant enhancement in protein expression was achieved through the optimization of expression parameters such as growth medium, induction point, inducer concentration, temperature, and duration of induction. The protein expresses in the form of insoluble non-functional inclusion bodies, which were further refolded and purified into its functionally active folded form. The protein shows the activity, nature, and conformational features very similar to the commercially available native version of the protein. The molecule could be a recombinant biosimilar of serratiopeptidase for therapeutic purposes and industry-relevant applications.

\section{Results}

\section{Recombinant cloning and development of mature} serratiopeptidase expression construct (pMSrp)

Formation of transparent halo around the point inoculated culture $\left(\sim 1 \times 10^{6} \mathrm{CFU}\right)$ of the bacteria was attributed to the presence of extracellular proteases (shown in Additional file 1: Figure S1a panel-ii). There was a prominent protein band visible around $50 \mathrm{kDa}$ molecular weight in SDS-PAGE gel, lane loaded with extracellular supernatant from $48 \mathrm{~h}$ grown bacterial culture (shown in Additional file 1: Figure S1b). Peptide mass fingerprinting of the corresponding protein band after trypsin digestion showed $51 \%$ sequence coverage with serralysin protease, also known as serratiopeptidase (shown in Additional file 1: Figure S2).

PCR amplified gene-specific to mature serratiopeptidase was $1416 \mathrm{bp}$ in size and ligated downstream to T7 promoter in $\mathrm{pET} 23 \mathrm{~b}(+)$ expression vector in between NdeI and XhoI restriction sites. The developed recombinant plasmid was termed pMSrp. Single digestion of recombinant plasmid pMSrp generated linearized vector pMSrp-SD and confirmed the size of the recombinant construct equivalent to 5081 bp (Fig. 1b MSrp-SD) while the double digestion with $N d e \mathrm{I}$ and $\mathrm{XhoI}$ resulted in two linear fragments of around $3600 \mathrm{bp}$ and $1416 \mathrm{bp}$ equivalent to the vector backbone and the serratiopeptidase (srp) gene insert respectively (Fig. 1b MsrpDD). Sequencing results along with restriction digestion results confirmed the successful cloning of the gene in
pET23b(+) vector and development of recombinant expression vector pMSrp.

\section{pMSrp expression seems toxic for $E$. coli cells, and only $E$. coli C43(DE3) cells expressed the protein correctly}

The number of transformed cells in the presence and absence of serratiopeptidase gene could explain the toxicity of the gene. The number of transformants in $E$. coli $D H 5-\alpha$ after transformation with $\mathrm{pET} 23 \mathrm{~b}(+)$ (no gene) and pMSrp (mature gene) were almost equal but were significantly different in other DE3 variants of $E$. coli, suggesting that the presence of gene had some deleterious effect on cells. Transformation of the plasmid pMsrp was not possible in E. coli BL21(DE3)cells despite repeated attempts, as shown in Fig. 2a. While in other DE3 variants, viz-C43(DE3), pLysS, and Rosetta(DE3)$p L y s S$ (RDP) number of successful transformants were significantly lesser than the vector alone (Fig. 2a).

When the protein expression was analyzed in different DE3 expression strains, the difference in protein expression was evident. Even after successful transformation, no visible protein expression was seen in E. coli BL21 (DE3)-pLysS cells ( $p L y s S)$ as visualized on SDS PAGE (Fig. $2 \mathrm{~b}$ induced $p L y s S$ lane). E. coli Rosetta (DE3)-pLysS cells (RDP) overexpressed a protein lesser than the actual size of mature serratiopeptidase, i.e., $50 \mathrm{kDa}$ (Fig. $2 \mathrm{~b}$ induced RDP-1 lane). Delayed induction of RDP cells; i.e., after $\mathrm{OD}_{600}>1.0$ resulted in the expression of the correct size protein representing $\sim 5 \%$ of total protein expression (Fig. 2b induced RDP-2 lane) in comparison to degraded overexpressed protein which was around $21 \%$ of total protein expression in the cell lysate. The maximal transformation was found in E. coli C43(DE3) cells (Fig. 2a pMSrp in C43). The cells were expressing the protein at correct size and were around $12 \%$ of the total protein (Fig. 2b induced C43 lane). Fractionation assay results shown in Fig. 2c confirmed the overexpressed protein corresponding to the mature serratiopeptidase expressed in the form of insoluble inclusion bodies and goes entirely in the pellet fraction,

\section{Optimization of expression parameters resulted in five-time more expression of mature serratiopeptidase in E. coli cells}

Without optimization, mature serratiopeptidase overexpression constituted about $12 \%$ of total protein expression in the form of insoluble inclusion bodies. Optimization of various physicochemical parameters was carried out with a hope of enhanced expression of recombinant protein. The point of induction was taken as first parameter for optimization, and this optimization alone enhanced the total cellular expression of mature serratiopeptidase by 1.46 times, the expression obtained 
at optical density $\sim 0.6-0.8$. The total protein expression was $25.9 \%$ at the optical density of $0.5-0.6$ in comparison to $17.7 \%$ at $0.6-0.8$ optical density measured at $600 \mathrm{~nm}$ (Fig. 3a, Sections 1 and 2).

Effect of nutrient medium composition on mature serratiopeptidase overexpression was measured by analyzing the expression in three complex nutrient media compositions viz-Luria broth, 2YT broth, and Terrific broth. 2YT broth showed the maximum expression, comprising $44 \%$ of the total expression. The addition of glucose at $1 \%$ $(\mathrm{w} / \mathrm{v})$ negatively affected the level of protein expression, irrespective of the growth media composition (Fig. 3b, Sections 1 and 2). The next parameter chosen for an optimization was inducer concentration. RNA polymerase found in T7-promoter based vectors is lactose inducible. IPTG, a synthetic structural analog of lactose is preferred over lactose since it cannot be metabolized, so the concentration of inducer remains constant throughout the induction. The overexpression of mature serratiopeptidase varied from 25 to $44 \%$ at different concentrations of inducer ranging between 0.1 and $2 \mathrm{mM}$ (Fig. 4a, Section 1). The maximum recombinant protein expression was observed at $0.8 \mathrm{mM}$, which was $45.4 \pm 1.76 \%$ of total protein expressed (Fig. 4a, Section 2). Change in temperature does not have any significant effect on protein expression or solubility. Less expression of mature serratiopeptidase was visible at $30{ }^{\circ} \mathrm{C}$ in comparison to $37^{\circ} \mathrm{C}$. Induction at $25^{\circ} \mathrm{C}$ or $18{ }^{\circ} \mathrm{C}$ shown no visible expression of recombinant protein when observed on SDS-PAGE, as evident in Fig. 4b, Section 1. The optimal temperature for serratiopeptidase expression was $37{ }^{\circ} \mathrm{C}$, where expressed mature serratiopeptidase constituted about $45 \%$ of total protein expression. Post-induction duration for maximal expression was optimized between 2 and $14 \mathrm{~h}$. The maximal expression of recombinant mature serratiopeptidase was found after $6 \mathrm{~h}$ of induction contributing $57.9 \pm 0.73 \%$ of total intracellular protein expression (Fig. 4b, Section 2).

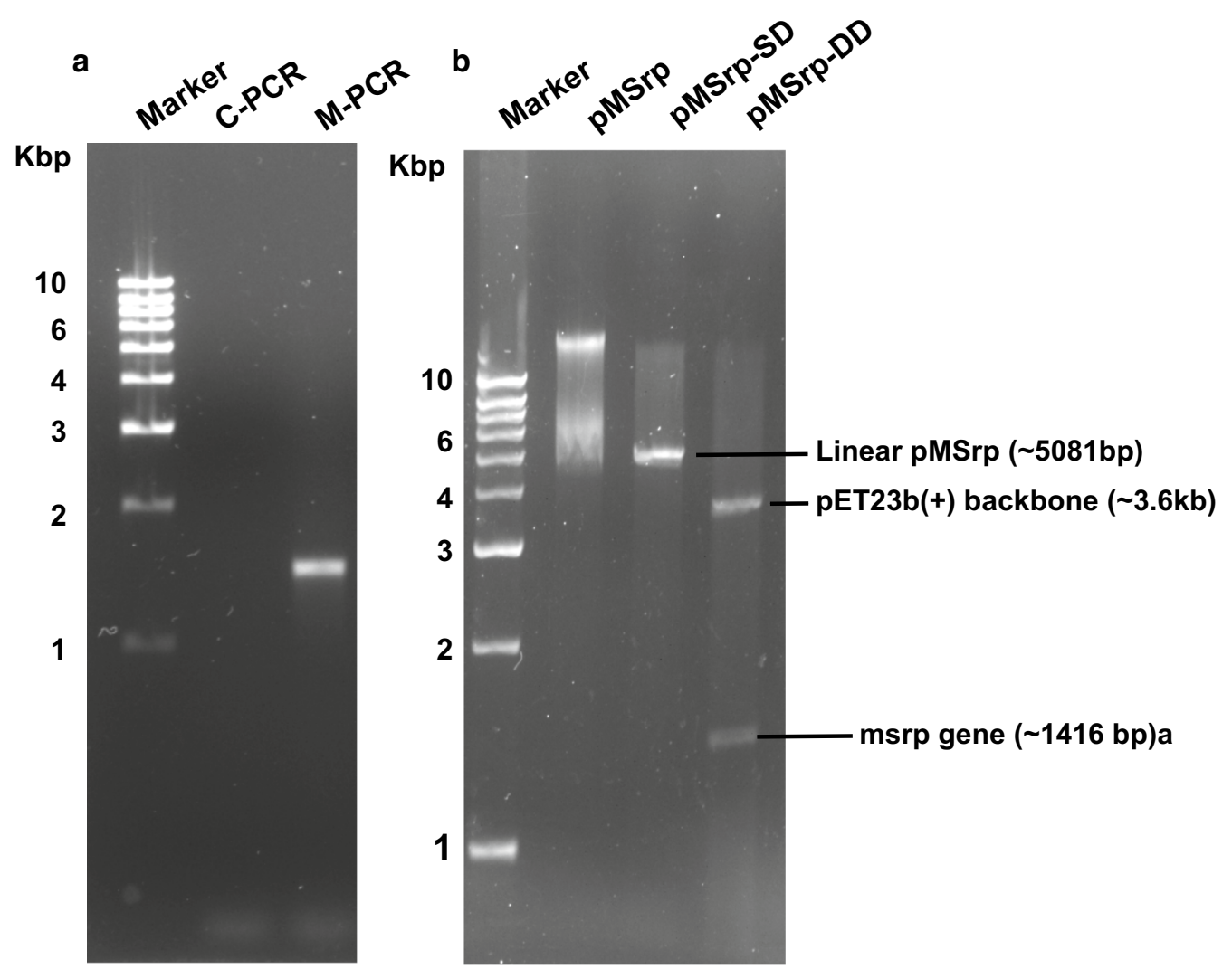

Fig. 1 Recombinant cloning and development of mature serratiopeptidase specific expression construct. a Representative Agarose gel (1.2\%) showing amplification of 1500 bp gene fragment, particular to the size of mature serratiopeptidase gene (M-PCR). The gene cloned in the pET23b(+) vector having Amp ${ }^{r}$ for selection. When digested with single restriction enzyme; i.e. Ndel and two different enzymes; i.e., Ndel and Xhol. b Representative agarose gel (1.2\%) shows a linear fragment (pMSrp-SD) of $\sim 5000$ bp and two fragments equal to the size of plasmid backbone 3600 bp and insert gene (MSrp) 1500 bp in Lane (pMSrp-DD) respectively confirming the successful insertion/ligation of gene and construction of recombinant plasmid 

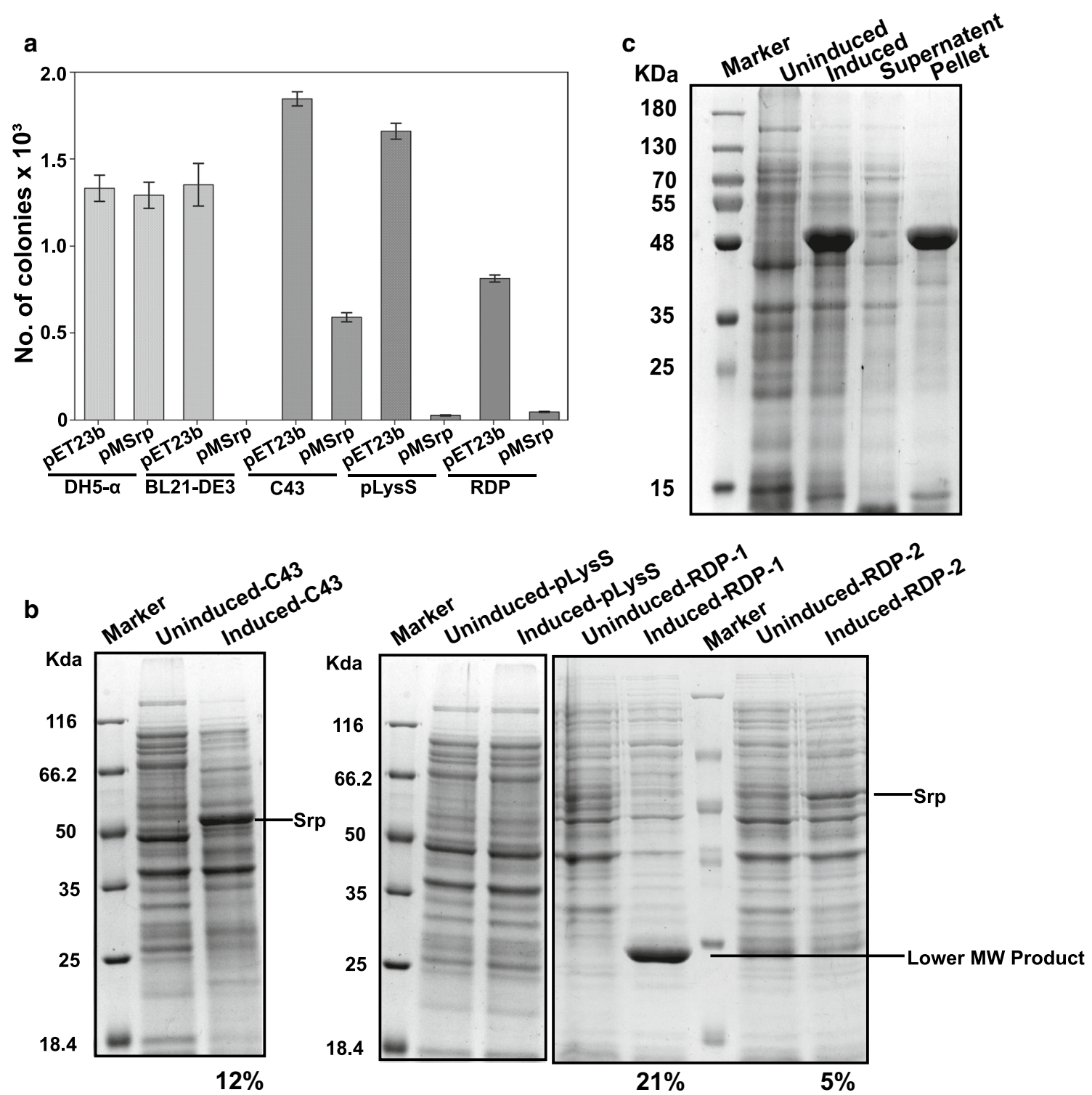

Fig. 2 Selection of E. coli expression host system and expression of mature serratiopeptidase. a Bar graph showing the number of pMSrp plasmid transformants in different E. coli expression host systems. DH5-a, BL21-DE3, C43, pLysS and RDP represents the E. coli cloning and expression strains E. coli DH5-a, E. coli BL21 (DE3), E. coli C43(DE3), E. coli BL21 (DE3)-pLysS, and E. coli Rosetta (DE3)-pLysS respectively. b Representative SDS-PAGE gel lanes are showing expression of mature serratiopeptidase gene product in different $E$. coli expression systems. While E. coli C43(DE3) cells express protein at the correct size, in other systems, there is either no visible expression (Induced-pLysS) or degraded expression (Induced-RDP-1) unless induced at optical density $>1.0$ at $600 \mathrm{~nm}$ (induced-RDP-2). The percentage contribution of the mature serratiopeptidase in total expressed protein either at correct molecular weight or in the degraded form is mentioned below the gel lanes. c Representative 12\% SDS-PAGE gel showing total cell lysate of uninduced and induced cell fractions of E. coli C43(DE3) cells showing overexpression of protein equivalent to $50 \mathrm{KDa}$. Fractionated samples of cell lysate loaded on SDS-PAGE shows the mature serratiopeptidase expresses in the form of insoluble inclusion bodies and completely goes into the insoluble fraction; i.e., pellet

The presence of plasmid pMSrp slowed down the growth rate of $E$. coli cells

Bacterial cells transformed with plasmid-irrespective of its type or gene insert show differences in growth rate in comparison to non-transformed cells. These differences are resultant of altered internal energetics of the bacterial cells and affect the production rate of recombinant proteins. The growth kinetics of E. coli C43(DE3) cells was observed in the presence and absence of mature serratiopeptidase specific gene under uninduced as well as 
induced conditions. The E. coli C43(DE3) cells without any presence of plasmid as well as inducer were taken as a negative control. The obtained growth curve of $E$. coli C43(DE3) cells for 12-h duration, as shown in Fig. 5, was used for measuring the specific growth rate of the bacterium in different conditions. All the transformed cells showed a decrease in growth rate as compared to the wild-type E. coli C43(DE3) cells. It was also evident that the presence of IPTG as inducer significantly decreased the growth rate. The calculated specific growth rate of $E$. coli C43-de3 cells in each condition are summarized in Table 1.

\section{Refolding and purification of isolated inclusion bodies provided homogenous enzymatically active serratiopeptidase}

125-135 mg serratiopeptidase inclusion bodies were obtained from a liter of grown culture, which was about $55 \%$ pure. Only the washing of inclusion bodies provided a $10 \%$ enhancement in the purity level, giving $100-$ $120 \mathrm{mg}$ of $60-65 \%$ pure inclusion bodies (Fig. 6a). The refolding efficiency of the protein was around $50 \%$, and 55-60 mg refolded and enzymatically active recombinant mature serratiopeptidase was obtained after the rapid dilution (1:100) and concentration. The protein prepared through refolding has purity around 85-90\% measured through SDS-PAGE (Fig. 6b). The trace amount of denaturants and protein contaminants were removed through size-exclusion chromatography, providing a yield of 45-50 mg $>98 \%$ pure functionally active recombinant mature serratiopeptidase (Fig. 6c). The yield measurement of enzymatically active refolded recombinant mature serratiopeptidase from 11 of bacterial culture as measured by Bradford assay, densitometric analysis, and activity assay are given below in Table 2 .

Azocasein based proteolytic assay suggests the specific activity of purified refolded recombinant mature serratiopeptidase was $1750 \pm 5 \mathrm{EU} / \mathrm{mg}$ in comparison to commercial standard showing $\sim 1820 \pm 5 \mathrm{EU} / \mathrm{mg}$ (Fig. 6d).

\section{Recombinant version mature serratiopeptidase could be a potential biosimilar to the native counterpart of the protein}

Native-PAGE, along with analytical HPLC results, concluded purified recombinant mature serratiopeptidase was homogenous preparation of functionally active monomeric molecules (Fig. 7a, b). The elution peak of
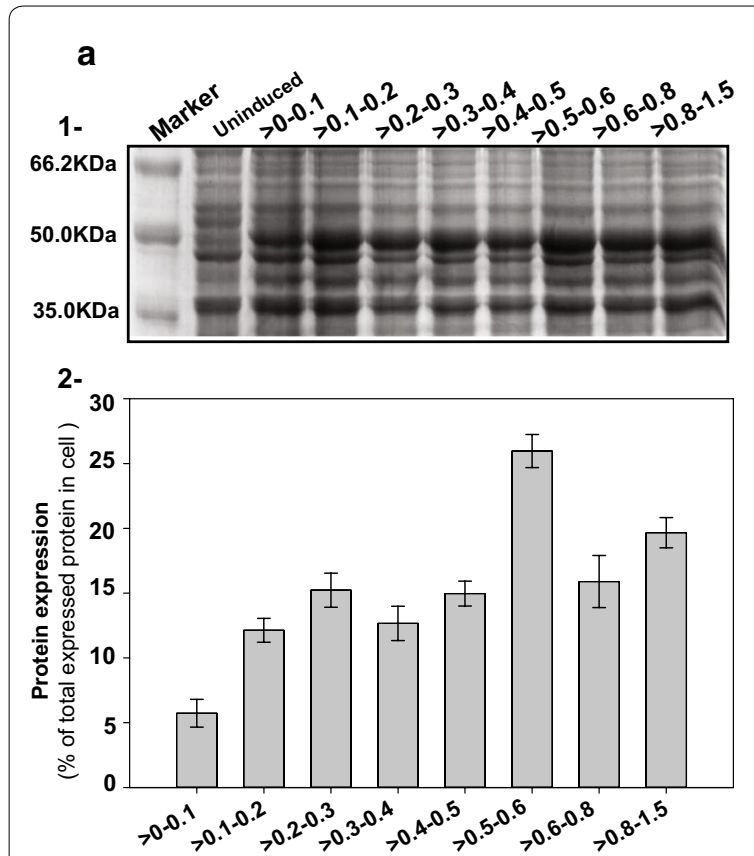

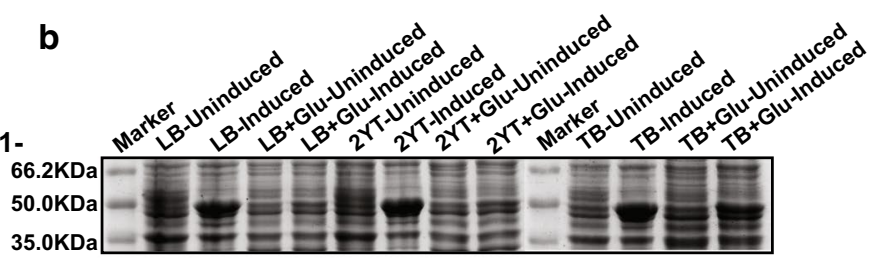

2-

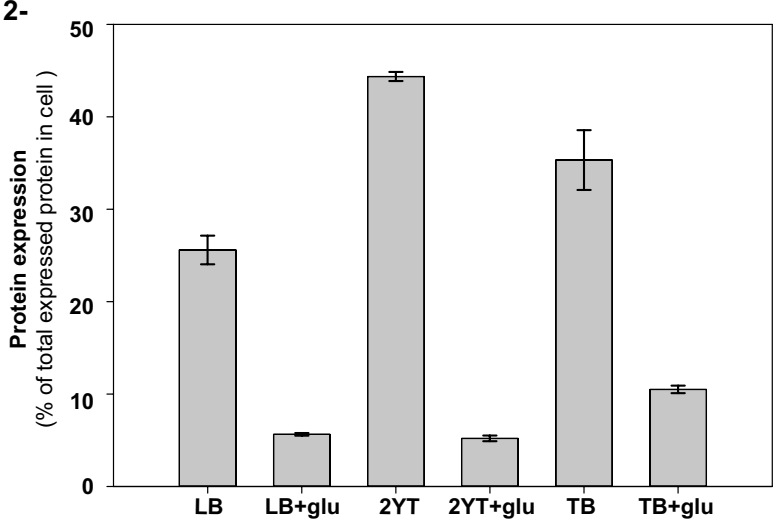

Fig. 3 Optimization of serratiopeptidase expression in E. coli C43(DE3) cells. a Effect of induction on overexpression of mature serratiopeptidase in E. coli C43(DE3) cells at different time points of growth was observed by supplementing culture with $1 \mathrm{mM} \mathrm{IPTG.} \mathrm{Section} 1$ shows the SDS-PAGE gel loaded with induced samples at different time points. Section 2 shows the bar graph plot representing the relative expression percentage of mature serratiopeptidase as the average of three independent densitometric analysis. Section 1 of part $\mathbf{b}$ shows the overexpression profile of the recombinant version of mature serratiopeptidase in different growth media on 12\% SDS-PAGE gel. Obtained percent values of serratiopeptidase expression in terms of total intracellular protein expression was averaged out for three independent densitometric analysis and used for plotting the bar graph shown in Section-2 of part-b 


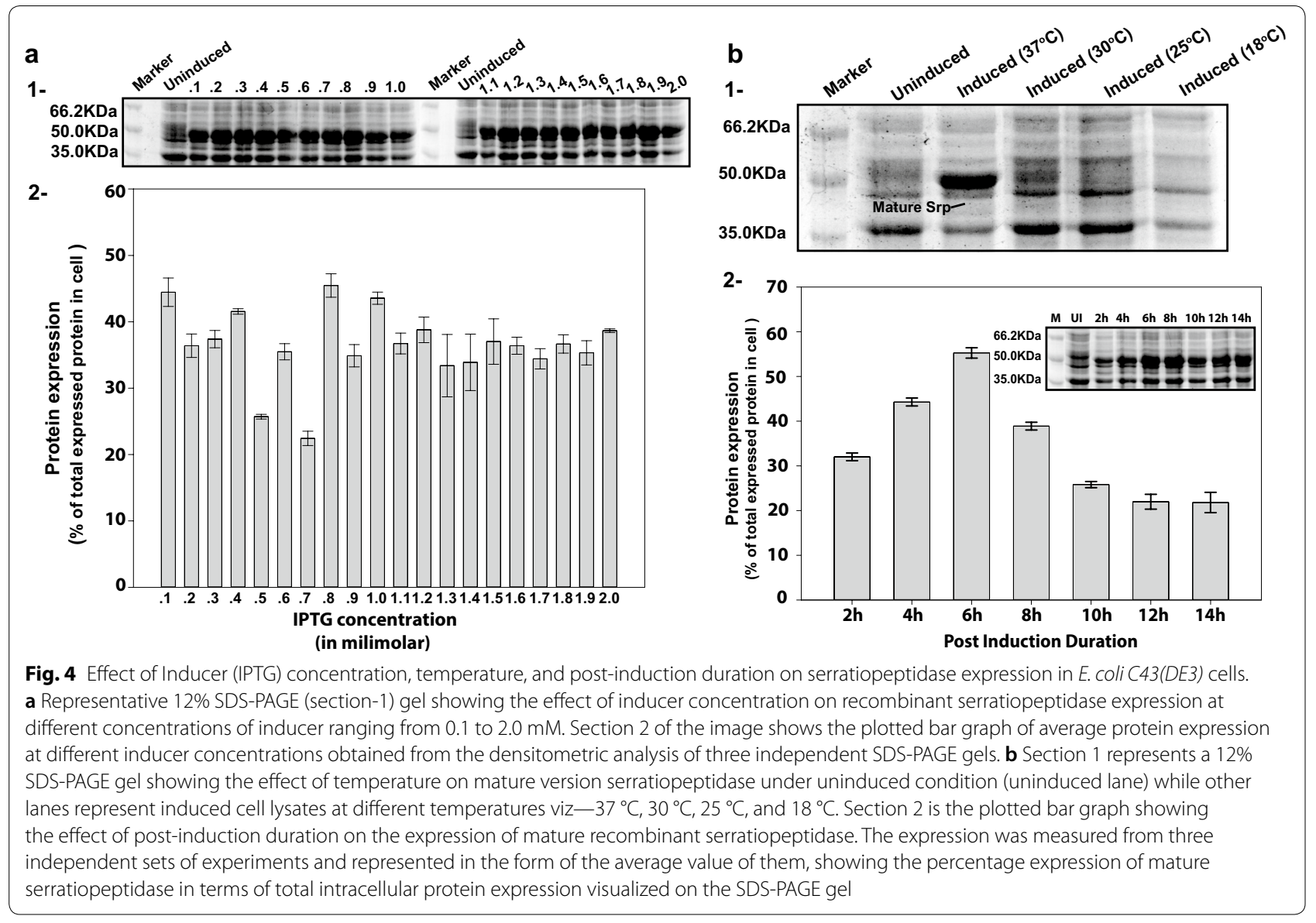

recombinant preparation coincided with the commercial version standard eluting at $7.5 \mathrm{ml}$.

In-gel trypsin digestion and peptide mass fingerprinting analysis of generated peptide fragments matched with $S$. marcescens serratiopeptidase protein having a sequence coverage of $53 \%$ (shown in Additional file 1: Figure S3). Circular dichroism (CD) spectra, as well as intrinsic fluorescence spectra of recombinantly prepared mature serratiopeptidase, were very similar to the commercially available serratiopeptidase (Fig. 7c). Similarly, the intrinsic fluorescence emission maxima were 339 and $338 \mathrm{~nm}$ for mature recombinant version and the commercial standard respectively and were identical, as shown in (Fig. 7d).

\section{Discussion}

Considering the therapeutical and industrial importance of serratiopeptidase [22, 24], in the present work, we focussed on the development of a recombinant DNA based methodology for the production and purification of serratiopeptidase in E. coli system. The prominent protein band around $50 \mathrm{kDa}$ in the extracellular secretion of S. marcescens mtcc7298 strain was the major extracellular protease of the bacteria called serratiopeptidase [15, 38]. The developed recombinant expression construct pMSrp contains the gene-specific to mature serratiopeptidase gene lacking the $\mathrm{N}$-terminal pro-peptide encoding nucleotides [35] located downstream to T7 promoter and can be transcribed in $E$. coli expression strains encoding $\mathrm{T} 7$ RNA polymerase.

When the gene was transformed into different $E$. coli expression systems, differences in the number of transformants was evident, which could be correlated to the toxicity of the gene. E. coli BL21 (DE3) cells repeatedly failed during transformation, and not a single colony was formed on the plate. E. coli C43(DE3) cells designed by Miraux and Walker contains two mutations in -10 region of lacUV5, which allows better overexpression of membrane proteins. The strain also provides stability to plasmids encoding toxic genes and allows the expression of recombinant proteins seems to be toxic in other E. coli DE3 variants [39]. When pMSrp transformed in $C 43(D E 3)$ cells, not only the maximum number of transformants was formed in E. coli C43(DE3) cells but also the transformed cells expressed serratiopeptidase protein efficiently. 


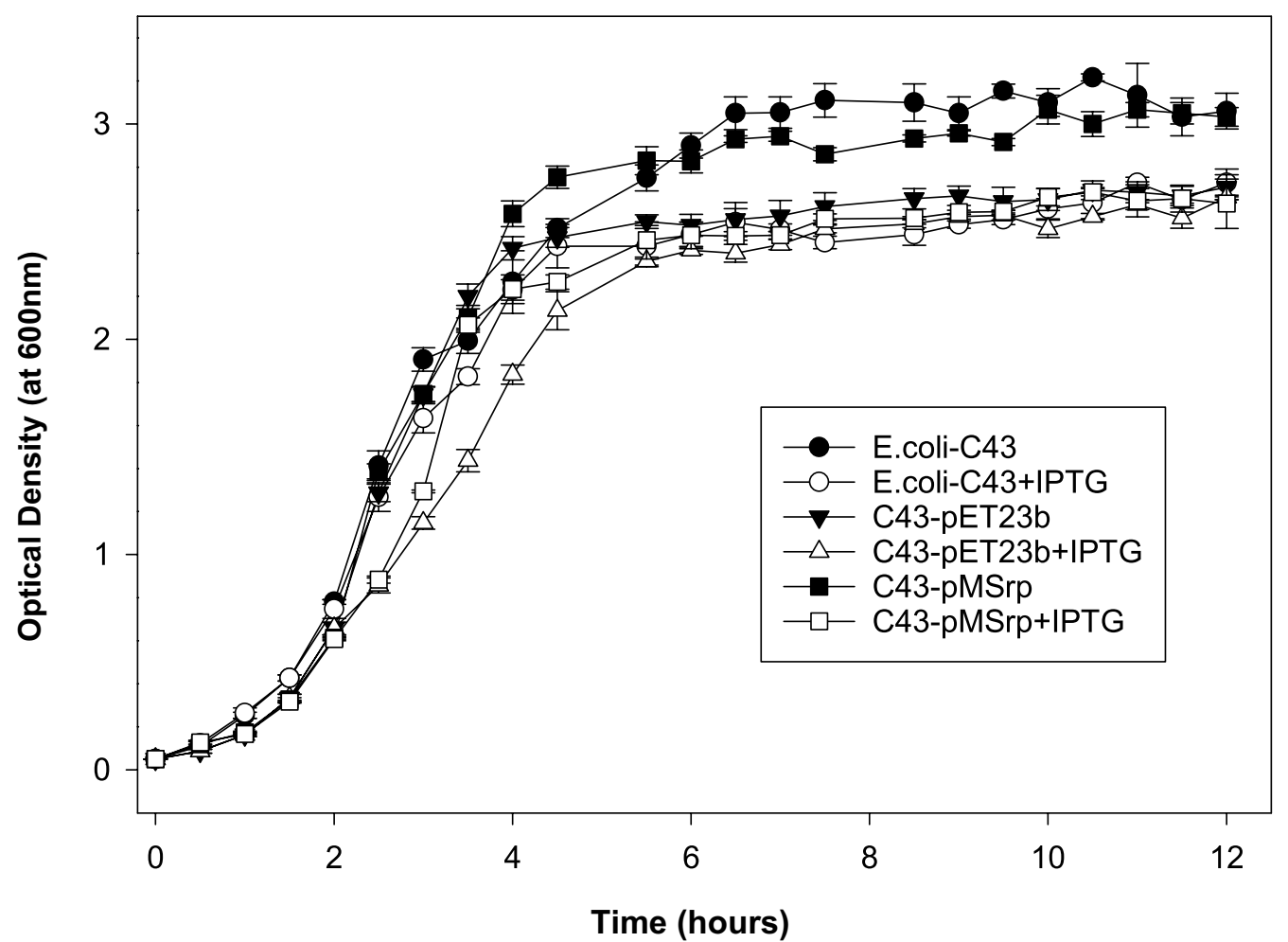

Fig. 5 Effect of inducer and different vector constructs on growth kinetics of E. coli C43(DE3) cells

Table 1 Specific growth rate constants $(\mu)$ for the growth of $E$. coli $C 43(D E 3)$ cells under different conditions at $37^{\circ} \mathrm{C}$

\begin{tabular}{ll}
\hline Conditions & $\begin{array}{l}\text { Specific growth } \\
\text { rate }(\boldsymbol{\mu})\left(\mathbf{h}^{-\mathbf{1}}\right)\end{array}$ \\
\hline E. coli C43(DE3) cells & 0.5604 \\
E. coli C43(DE3)+ IPTG & 0.6044 \\
E. coli C43(DE3)-pET23b & 0.5464 \\
E. coli C43(DE3)-pET23b + IPTG & 0.6091 \\
E. coli C43(DE3)-pMSrp & 0.5965 \\
E. coli C43(DE3)-pMSrp + IPTG & 0.7091 \\
\hline
\end{tabular}

Although a good number of transformants were possible in other E. coli BL21 (DE3) variants, viz-E. coli BL21 (DE3)-pLysS, E. coli Rosetta (DE3)-pLysS, they all failed at the protein expression level which could be attributed to protease associated cytotoxicity [39, 40]. The correct and maximum serratiopeptidase expression was found in E. coli $C 43(D E 3)$ cells, which was $~ 12 \%$ of total protein expression resulting in purification of around $2-2.5 \mathrm{mg}$ functionally active serratiopeptidase from 1-1 of culture.

Recombinant version mature serratiopeptidase exclusively formed insoluble aggregates, i.e., inclusion bodies. Optimization of overexpression process parameters such as induction point, temperature, inducer concentration., results in enhancement of correct folding hence solubility of the protein. It also aids in the enhancement of the yield of the recombinant protein of interest [41]. Considering these two factors, vizsolubility and yield, optimization of various process parameters was carried out, which resulted in 5 times more expression of the protein providing around 20 times more yield in the form of 40-45 mg functionally active pure mature serratiopeptidase from 1-1 of culture. No effect of process parameter optimization was seen on the solubility of the protein. Temperature optimization further confirmed the toxicity of the protein since no visible expression of the protein was found at lower temperatures, i.e., 25 and $18{ }^{\circ} \mathrm{C}$. Failure in achieving the soluble protein and expression of the protein in the form of inclusion bodies could be attributed to $\mathrm{pH}$, osmolarity, redox potential, cofactors, and folding differences in the intracellular microenvironment since the protein is an extracellular protein [33, 42]. Usually, when the expression of recombinant protein goes beyond $2 \%$ of the total cellular protein, it results in unregulated accumulation of the protein insoluble aggregates known as inclusion bodies [43]. Inclusion 

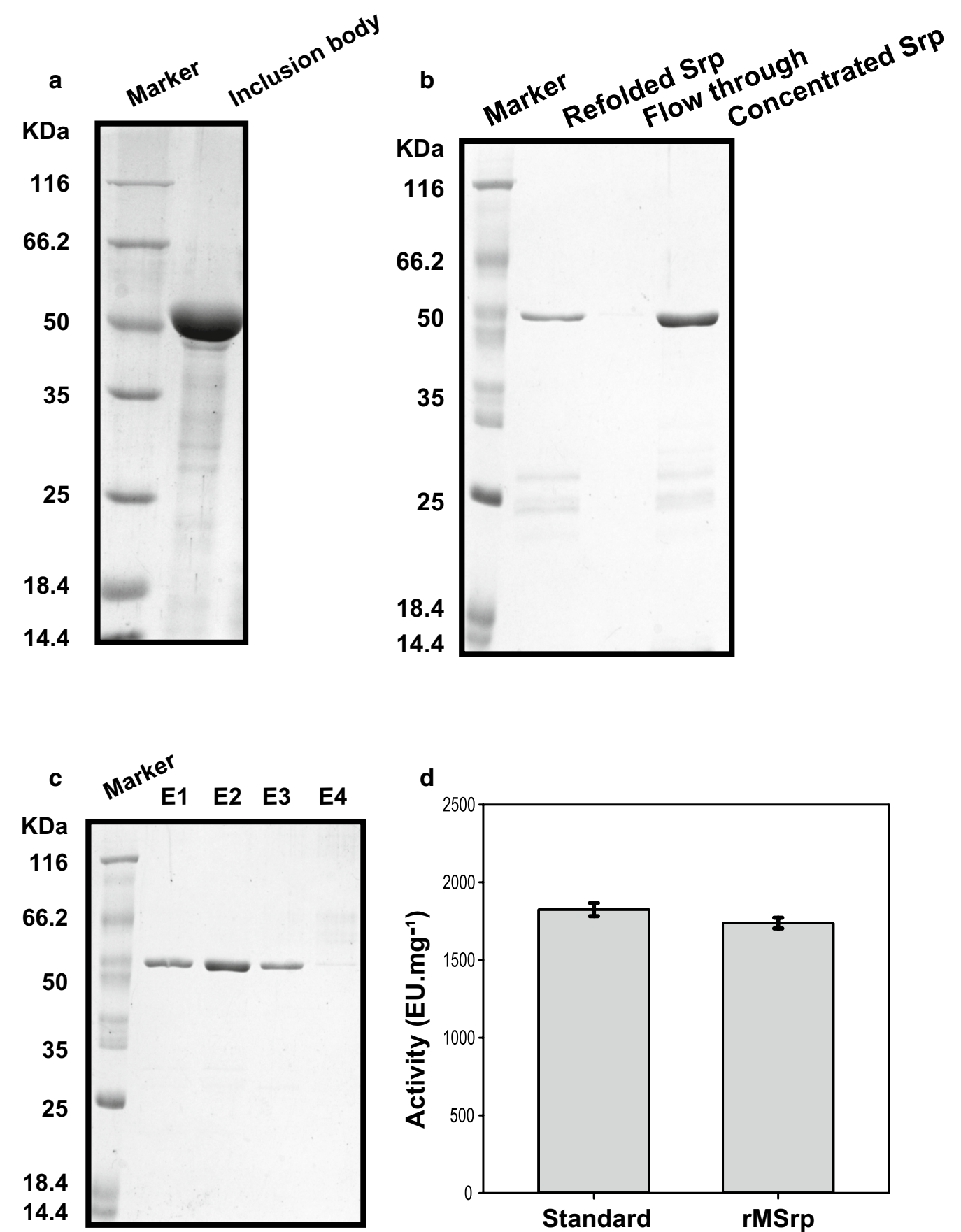

Fig. 6 Purification of recombinant mature serratiopeptidase and proteolytic activity assay. Representative SDS-PAGE gels showing a isolated inclusion body (IB) of recombinant version mature serratiopeptidase from $6 \mathrm{~h}$ grown induced culture of E. coli C43(DE3) cells harbouring the expression plasmid pMSrp, $\mathbf{b}$ refolded serratiopeptidase by rapid dilution in ice-cold refolding buffer (refolded srp lane) and protein profile after concentration (concentrated srp). The lane Flow through was loaded with filtrate collected during concentration using $30 \mathrm{kDa}$ molecular weight cut-off during concentration. c Representative SDS-PAGE gel showing collected elution fractions (E1-E4) of purified refolded mature version recombinant serratiopeptidase by size exclusion chromatography. $\mathbf{d}$ Protease activity of purified mature recombinant serratiopeptidase (rMSrp) its commercially available wild counterpart (standard) was measured using azocasein as substrate. The obtained specific activity of each one is plotted in the form of bar graph with error bars representing the standard error calculated from three independent experiments 
Table 2 Protein yield comparison at different steps of purification of the recombinant version of mature serratiopeptidase

\begin{tabular}{llll}
\hline Step & Yield $(\mathbf{m g})$ & Purity (\%) & Activity (EU/mg) \\
\hline Isolation & $130 \pm 5$ & 55 & Not measured \\
Washing & $110 \pm 10$ & $60-65$ & Not measured \\
Refolding by dialysis & $57.5 \pm 2.5$ & $85-90$ & $1650 \pm 5 \mathrm{EU} / \mathrm{mg}$ \\
Gel filtration & $47.5 \pm 2.5$ & $>98$ & $1750 \pm 5 \mathrm{EU} / \mathrm{mg}$ \\
\hline
\end{tabular}

bodies formed during heterologous overexpression constitute $50-60 \%$ of the recombinant protein of interest, having the presence of fewer protein impurities [44] and could serve a better source of protein preparation if the proper method of their solubilization and refolding could be devised. A variety of proteins are successfully recovered from accumulated inclusion bodies, which are conformationally and functionally, similar to the native protein [45]. Inclusion bodies representing mature serratiopeptidase were isolated from E. coli C43(DE3) cells and refolded in ice-cold refolding buffer with an efficiency of around $50 \%$. The purified mature serratiopeptidase from refolded inclusion bodies was identical to the commercially available native version on the molecular level (monomeric) as well as functional level (activity assay). Comparison of the secondary and tertiary structure of recombinant one with the commercial one through circular dichroism and intrinsic fluorescence emission suggests both are very similar. The specific activity of recombinant version is comparable to the native version, and it could serve as a recombinant biosimilar for a variety of biotechnological and industrial applications.

\section{Conclusions}

It is nearly impossible to express proteases in E. coli as a functional protein due to their associated catalytic activity. Unregulated intracellular expression of proteases often results in cell death, hindrance in growth, lack of expression, degraded expression, or expression of the

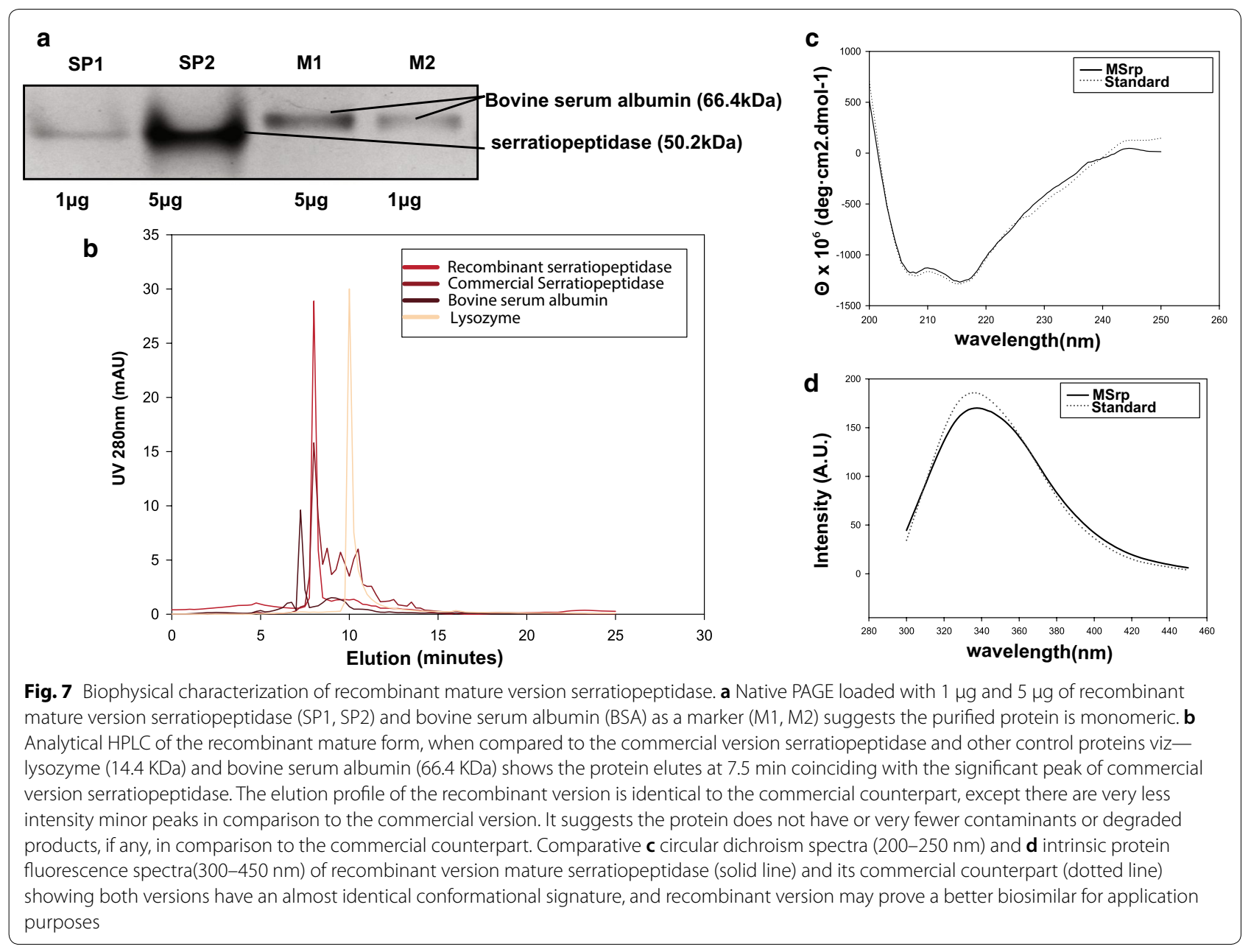


gene product in the form of insoluble inclusion bodies. In the present work, we specifically tried to explore the recombinant expression, purification, and physicochemical comparison of an industrially and therapeutically relevant broad specificity extracellular metalloprotease of S. marcescens (MTCC7298) known as serratiopeptidase. A recombinant expression plasmid pMSrp exclusive to the expression of mature serratiopeptidase lacking 16 amino acid long $\mathrm{N}$-terminal propeptide was constructed by cloning the mature serratiopeptidase specific gene under T7 promoter in $\mathrm{pET} 23 \mathrm{~b}(+)$ vector plasmid. Transformation and expression in different $E$. coli expression host systems confirmed the presence of the gene is toxic for the cells causing either unsuccessful transformation (BL21(DE3) cells), lack of expression (BL21(DE3)$p L y s S$ cells) or expression of the degraded product (Rosetta(DE3)-pLysS cells). Only E. coli C43(DE3)cells, engineered specifically for the expression of membrane proteins and toxic proteins, were expressing the protein correctly in the form of intracellular insoluble deposits, i.e., inclusion bodies.

Further optimization of various process parameters resulted in about five times more expression of serratiopeptidase than unoptimized conditions (by densitometric analysis). The overexpressed mature version of serratiopeptidase protein forms $60-65 \%$ pure inclusion bodies. Solubilization, refolding, and purification provides purified (>98\%) 45-50 mg functionally active protein from one-liter culture. The discussed recombinant approach could be a better alternative to the present traditional production strategy, considering the health hazards associated with wild strains of $S$. marcescens. The biological identity, activity, and biophysical comparison with commercially available native serratiopeptidase suggest the recombinant version could serve as a potential biosimilar for pharmaceutical and variety of industrial applications.

\section{Methods \\ Screening of serratiopeptidase producing Serratia marcescens strain}

Serratia marcescens strain (collection id-7298), collected from the Microbial Type Culture Collection (MTCC), IMTECH Chandigarh was screened for the extracellular secretion of serratiopeptidase. $0.2 \mu \mathrm{l}$ overnight grown seed culture of $S$. marcescens was point inoculated on $1 \%$ skimmed milk agar plate following 48-h incubation at $37{ }^{\circ} \mathrm{C}$. The identity of protease in secretion was confirmed by SDS-PAGE and further by In-gel trypsin digestion and Peptide mass fingerprinting using MALDI-TOF mass spectroscopy.

\section{Gene amplification and recombinant cloning}

Mature serratiopeptidase gene-specific forward and reverse primers (shown in Table 3) were used for PCR based amplification of the mature serratiopeptidase (Msrp) gene, which lacks the initial 48 nucleotides encoding $\mathrm{N}$-terminal propeptide. In brief-The reaction mixture contained $200 \mu \mathrm{m}$ dNTPs (New England Biolabs, USA), $1 \times$ high fidelity buffer (Thermo Scientific, USA), and 4.5 units of Phusion polymerase (Thermo Scientific, USA) and $0.2 \mathrm{ng} / \mu \mathrm{l}$ genomic DNA of $S$. marcescens mtcc7298 as template DNA. Amplification reaction comprised of an initial $3 \mathrm{~min}$ denaturation $\left(95^{\circ} \mathrm{C}\right), 35$ cycles of $30 \mathrm{~s}$ denaturation $\left(95^{\circ} \mathrm{C}\right), 30 \mathrm{~s}$ annealing $\left(\mathrm{T}_{\mathrm{a}}=59^{\circ} \mathrm{C}\right)$, and $90 \mathrm{~s}$ extension $\left(72^{\circ} \mathrm{C}\right)$ each, followed by a final 10 min extension $\left(72^{\circ} \mathrm{C}\right)$. A control reaction was put together containing all the components except the template DNA.

Amplified PCR product and empty pET23b(+) vector were digested for $6 \mathrm{~h}$ by restriction enzymes NdeI and XhoI (New England Biolabs, USA). Purified PCR product and vector after digestion were allowed to ligate at $16{ }^{\circ} \mathrm{C}$ for the overnight duration by T4 DNA ligase (New England Biolabs, USA). The ligated product was transformed into competent $E$. coli $\mathrm{DH} 5 \alpha$ and plated on ampicillin $(200 \mu \mathrm{g} / \mathrm{ml})$ agar plates. Positive transformants containing the ampicillin-resistant gene $\left(A m p^{r}\right)$ were verified through colony PCR.

Restriction digestion of the recombinant plasmid was carried out to verify the size and successful insertion of msrp in the expression vector by visualizing the fragment, equivalent to the size of the cloned gene on $1 \%$ agarose gel. Sequencing of the expression plasmid was performed to verify the sequence using T7 promoter and terminator specific primers (Base Asia, Singapore).

\section{E. coli strain optimization}

Different E. coli BL21(DE3) based expression host cells were screened to find an optimal expression host for pMSrp expression. Freshly prepared $\mathrm{CaCl}_{2}$ chemical competent cells $\left(1.3 \times 10^{7}\right)$ of four different $E$. coli expression strains, viz-E. coli BL21(DE3), E. coli C43(DE3), E. coli BL21(DE3)-pLysS and E. coli Rosetta(DE3)-pLysS were transformed by $10 \mathrm{ng}$ of $\mathrm{pET} 23 \mathrm{~b}(+)$ null vector and recombinant plasmid pMsrp. The positive transformants were enumerated in each strain, and the number of viable cells was taken as a criterion to select the optimal host strain. The number of transformants in E. coli DH5- $\alpha$ was taken as a positive control. Strains found to be successfully transformed with pMSrp were screened for optimal protein expression. Transformed cells of different $E$. coli expression strains were grown at $37^{\circ} \mathrm{C} 220 \mathrm{rpm}$ and induced by the addition of $1 \mathrm{mM}$ IPTG (SRL, India) when the optical density of the culture at $600 \mathrm{~nm}$ reached to 0.6-0.8. Bacterial cultures were allowed to grow for $2 \mathrm{~h}$ at 
similar growth conditions before visualizing overexpression through SDS-PAGE.

\section{Protein expression and solubility assessment}

Protein overexpression was visualized by loading normalized amount of the induced, and uninduced cell lysates on a 12\% SDS_PAGE and viewed after coomassie staining. The level of overexpression was quantified through the densitometric analysis of the Gel bands. To assess the solubility of the overexpressed protein, collected cell pellets after $2 \mathrm{~h}$ of induction were lysed by sonication in resuspension buffer $(25 \mathrm{mM}$ Tris, $100 \mathrm{mM} \mathrm{NaCl}$, and $\mathrm{pH}$ 7.6). The insoluble content of the lysate was separated from the soluble part by centrifugation at $10,000 \times g$ $(10 \mathrm{~min}), 4^{\circ} \mathrm{C}$. The separated pellet from supernatant was dissolved in an equal volume of resuspension buffer supplemented with $6 \mathrm{M}$ urea. Normalized amount of uninduced, induced cell lysates, soluble and pellet fraction was loaded on SDS-PAGE and analyzed after coomassie staining of the gel.

\section{Optimization of physicochemical parameters}

For maximal expression of mature serratiopeptidase in the opted E. coli expression strain, different physicochemical parameters, viz-growth media, Point of induction, Inducer concentration, the temperature during overexpression, post-induction duration were optimized. The optimal value for maximal expression was determined by variating one parameter at a time. Protein expression quantification at various points of process parameters was performed through densitometric analysis of separate lanes of SDS-PAGE representing different values of the physicochemical parameter under study.

\section{Densitometry analysis}

Coomassie blue-stained gels were imaged on Bio-Rad $\mathrm{XR}+$ (USA) gel documentation unit and analyzed by the Image-lab program (Bio-Rad, USA). The relative intensity of the band was measured to quantify the overexpression of the protein. The relative percentage of the expressed recombinant protein in whole cell lysate at particular conditions was measured by selecting the whole lane and detecting the band through the 'add band' option (band

\begin{tabular}{|c|c|c|}
\hline Oligonucleotides & Sequence & Restriction site \\
\hline Msrp_fwd_7298 & $\begin{array}{l}\text { 5'-TATAATACTCATATG } \\
\text { GCCGCGACAACC-3' }\end{array}$ & Ndel \\
\hline Msrp_rev_7298 & $\begin{array}{r}5^{\prime} \text {-ATGTACCTCGAGTTA } \\
\text { CACGATAAAGTCC-3' }\end{array}$ & Xhol \\
\hline
\end{tabular}

detection sensitivity was high: 75\%). A relative comparison of the overexpressed protein in different conditions was performed manually. The protein bands representing mature serratiopeptidase in each lane were selected through 'add band' option (band detection sensitivity was high: 75\%), and the area was trimmed using 'adjust band' option to minimize the background. The quantity of the selected band was measured through 'quantity tools' and selecting one of the overexpressed protein band (lowest range) as reference. The intensity obtained was preferred as criteria to determine the optimal condition for the maximal overexpression of recombinant mature serratiopeptidase. At least three independent gels for each condition were analyzed densitometrically, and the relative mean value was plotted.

\section{Growth profile and specific growth rate}

Escherichia coli C43(DE3) cells alone and transformed with pMsrp were grown at $37{ }^{\circ} \mathrm{C}$, with and without induction under shaking condition at $220 \mathrm{rpm}$. Aliquots of $500 \mu \mathrm{l}$ culture were withdrawn at $30 \mathrm{~min}$ interval until $12 \mathrm{~h}$ for optical density measurements. The turbidity of the samples were measured at $600 \mathrm{~nm}$ using Beckman UV-Spectrophotometer (USA). 1 mM IPTG was added in samples representing induced condition when the optical density of cultures at $600 \mathrm{~nm}$ reached 0.5-0.6. To calculate the specific growth rate constant, $\mu$, the exponential (or logarithmic) growth phase was preferred, during this phase, the rate of increase in the number of cells was proportional to the number of bacteria present at that time. The specific growth rate constant $\mu$ was determined by fitting the data into the exponential equation using systat sigmaplot 14.0.

Preparation of inclusion bodies, refolding, and purification Escherichia coli Bl21 C43(DE3) cells were harvested after $6 \mathrm{~h}$ of induction at $37{ }^{\circ} \mathrm{C} 220 \mathrm{rpm}$ by centrifugation at $10,000 \times g$ for $10 \mathrm{~min}$ at $4{ }^{\circ} \mathrm{C}$. Separated cells were resuspended in resuspension buffer (Tris: $50 \mathrm{mM}, \mathrm{NaCl}$ $350 \mathrm{mM}$, Beta-mercaptoethanol-5 mM pH-8.0) supplemented with $500 \mu \mathrm{g} / \mathrm{ml}$ lysozyme and lysed through sonication (Qsonica, Cole-Parmer USA) at 25\% amplitude (10 s ON $50 \mathrm{~s}$ OFF). The supernatant is separated from the insoluble pellet by centrifuging the solution at $15,000 \times g$ for $20 \mathrm{~min}$ at $4{ }^{\circ} \mathrm{C}$. The separated pellet representing the mature serratiopeptidase inclusion bodies were washed twice with wash buffer (Tris: $50 \mathrm{mM}$, EDTA: $5 \mathrm{mM} \mathrm{NaCl}-500 \mathrm{mM}$, Glycerol: $2 \%$, Beta-mercaptoethanol-5 mM, Triton-X-100:1.5\%, Urea: 2.5 Molar pH-6.8). Remaining detergent was removed by further washing the inclusion bodies with tris buffer $(50 \mathrm{mM}, \mathrm{pH} 7.4)$ and stored at $-80^{\circ} \mathrm{C}$ until purification. 
Inclusion bodies dissolved in $1 \mathrm{ml}$ denaturing buffer (Tris: $50 \mathrm{mM}, \mathrm{NaCl}$ : $500 \mathrm{mM}, 6$ Molar Guanidinium hydrochloride, $\mathrm{pH}$ 7.6) were refolded by dialysis against ice-cold refolding buffer (Tris: $25 \mathrm{mM}, \mathrm{NaCl}: 100 \mathrm{mM}$, $\mathrm{CaCl}_{2}: 5 \mathrm{mM}_{2} \mathrm{ZnCl}_{2}: 1 \mathrm{mM} \mathrm{pH}$ 7.6). The refolded protein fraction was separated from any misfolded/precipitated protein by centrifugation and filtration using a $0.2 \mu \mathrm{M}$ syringe filter (MDI, India). Remaining impurities and traces of denaturant were removed through superdex G-75 Hi-Prep 10/300 GL gel filtration column (GE Life Sciences) in refolding buffer lacking the $\mathrm{CaCl}_{2}$ and $\mathrm{ZnCl}_{2}$. The purity of the fractions collected during elution was assessed through activity assay, SDS-PAGE, and Coomassie staining.

\section{In-gel trypsin digestion and peptide mass fingerprinting (PMF)}

The protein band corresponding to the molecular weight of serratiopeptidase was manually excised, chopped into small pieces, and submerged in $25 \mathrm{mM} \mathrm{NH} \mathrm{mH}_{3}$ (Sigma Aldrich USA) containing $25 \mathrm{ng} / \mu \mathrm{l} \mathrm{MS}$ grade trypsin (Pierce, Thermo Scientific USA). Digested peptides were extracted in a $1: 1$ mixture of $0.1 \%$ Trifluoroacetic acid (Sigma Aldrich, USA) and Acetonitrile (Sigma Aldrich, USA), mixed with matrix solution and spotted on MALDI target plate. Generated peptide mass spectra were searched in the Mascot software search engine (Matrix Science, UK) [46].

\section{Yield and activity measurements}

The yield at different stages of refolding and purification was measured through Bradford assay, as mentioned by Kruger in a microplate format [47]. The activity of the commercial serratiopeptidase and recombinant serratiopeptidase was measured by a protease activity assay as suggested by Ruchel et al. [48] with slight modifications. Briefly, the $400 \mu \mathrm{l}$ reaction mixture containing $1 \%$ azocasein (SRL, India) and suitably diluted protein was incubated at $37^{\circ} \mathrm{C}$ for $30 \mathrm{~min} .150 \mu \mathrm{l}$ of $20 \%$ TCA (SRL, India) was added to stop the reaction and centrifuged for $5 \mathrm{~min}$ at $10,000 \times g$. The supernatant was added in an equal volume of $1 \mathrm{~N} \mathrm{NaOH}$ (Millipore Sigma, USA), and the absorbance was measured at $450 \mathrm{~nm}$. An increase of 0.1 absorption unit after $30 \mathrm{~min}$ of incubation at $37^{\circ} \mathrm{C}$ was taken as one enzyme unit (EU).

\section{Native PAGE and HPLC analysis}

Native PAGE analysis was done to assess the homogeneity and purity of the purified recombinant version mature serratiopeptidase. $10 \%$ non-denaturing gel lanes were loaded with mature version serratiopeptidase along with control samples of BSA. The gel was run at constant voltage $(80 \mathrm{~V})$ at $4{ }^{\circ} \mathrm{C}$ and visualized after coomassie staining.

Analytical HPLC of $20 \mu \mathrm{l}$ samples containing bovine serum albumin (BSA), lysozyme, recombinantly prepared, and commercial serratiopeptidase each containing $5 \mu \mathrm{g}$ protein were run was carried out on Bio SEC-5 HPLC column (Agilent Technologies, USA). The elution profile for each protein was used for further comparison and analysis.

\section{Circular dichroism and fluorescence emission spectra}

The secondary and tertiary structure profile of the purified and refolded mature version recombinant serratiopeptidase was analyzed through circular dichroism and fluorescence spectroscopy. In brief, one micromolar recombinantly prepared serratiopeptidase was scanned in Far-UV circular dichroism spectra, i.e. 200-250 nm in $1 \mathrm{~mm}$ path length cell using J-810 spectropolarimeter (Jasco, UK) flushed with nitrogen gas at $25^{\circ} \mathrm{C}$. Samples were scanned at a rate of $50 \mathrm{~nm} / \mathrm{min}$ with a step size of $1 \mathrm{~nm}$. Spectra were averaged over three scans and corrected for background by subtracting the scans of the buffer without protein.

Three independent intrinsic tryptophan fluorescence emission spectra of one micromolar protein were collected between 300 and $450 \mathrm{~nm}$ after excitation at $280 \mathrm{~nm}$ at $25{ }^{\circ} \mathrm{C}$ using carry eclipse fluorescence spectrophotometer (Agilent technologies USA) and averaged out. The circular dichroism profile and intrinsic fluorescence spectra in the same range given by one micromolar commercial version serratiopeptidase (Systopic Laboratories, India) were taken as a control for comparison.

\section{Supplementary information}

Supplementary information accompanies this paper at https://doi. org/10.1186/s12934-019-1267-x.

Additional file 1. Additional table and figures.

Abbreviations

BSA: bovine serum albumin; CD: circular dichroism; E. coli: Escherichia coli; IPTG: isopropyl $\beta$-D-1-thiogalactopyranoside; pMSrp: plasmid for mature serratiopeptidase expression; msrp: mature serratiopeptidase gene; TFA: trifluoroacetic acid; TCA: trichloroacetic acid; RDP: Rosetta (DE3)-pLysS.

\section{Acknowledgements}

VS acknowledges UGC, Govt. of India for awarding fellowship for the doctoral research SM acknowledges DST for the scholarship received for junior research fellow position. Authors acknowledge Prof. U. C. Banerjee, National Institute of Pharmaceutical Education and Research, Mohali Chandigarh, for helping us out in the procurement of Serratia marcescens mtcc7298 strain. The authors acknowledge the efforts made by Jon Tally, Kansas City, USA, for carefully reading the manuscript. 


\section{Authors' contributions}

VS and TKC planned the work. VS and TKC conceived and designed the experiments. VS and SM executed all the experiments. VS, SM, and TKC analyzed the results, compiled, reviewed, and revised the manuscript. All authors read and approved the final manuscript.

\section{Funding}

No financial aid has been received from external funding agencies for executing the work. The authors acknowledge the infrastructural support from the Indian Institute of Technology, Delhi, India.

\section{Availability of data and materials}

(1) The datasets used and/or analyzed during the current study are available from the corresponding author on reasonable request. (2) All data generated or analyzed during this study are included in this published article.

\section{Ethics approval and consent to participate}

Not applicable.

\section{Consent for publication}

Not applicable.

\section{Competing interests}

An Indian patent application (201811029173) has been filed for the technology/invention disclosed in the present work.

Received: 9 August 2019 Accepted: 6 December 2019 Published online: 17 December 2019

\section{References}

1. Rawlings ND, O'Brien E, Barrett AJ. MEROPS: the protease database. Nucleic Acids Res. 2002;30(1):343-6.

2. Gosalia DN, Salisbury CM, Ellman JA, Diamond SL. High throughput substrate specificity profiling of serine and cysteine proteases using solution-phase fluorogenic peptide microarrays. Mol Cell Proteomics. 2005;4(5):626-36

3. Kalisz HM. Microbial proteinases. In: Enzyme studies. Berlin: Springer; 1988. p. 1-65

4. Tavano OL, Berenguer-Murcia A, Secundo F, Fernandez-Lafuente R. Biotechnological applications of proteases in food technology. Compr Rev Food Sci Food Saf. 2018;17(2):412-36.

5. Singh S, Bajaj BK. Potential application spectrum of microbial proteases for clean and green industrial production. Energy Ecol Environ. 2017;2(6):370-86

6. Raveendran S, Parameswaran B, Ummalyma SB, Abraham A, Mathew AK, Madhavan A, et al. Applications of microbial enzymes in food industry. Food Technol Biotechnol. 2018;56(1):16-30.

7. Sherry S, Fletcher AP. Proteolytic enzymes: a therapeutic evaluation. Clin Pharmacol Ther. 1960;1(2):202-26.

8. Klasen $\mathrm{HJ}$. A review on the nonoperative removal of necrotic tissue from burn wounds. Burns. 2000;26(3):207-22.

9. Ramundo J, Gray M. Enzymatic wound debridement. J Wound Ostomy Cont Nurs. 2008;35(3):273-80.

10. Esmon CT. The endothelial protein $C$ receptor. Curr Opin Hematol. 2006;13(5):382-5

11. Craik CS, Page MJ, Madison EL. Proteases as therapeutics. Biochem J. 2011:435(1):1-16.

12. Anil CS, Kashinath MA. Production, characterization \& optimization of potent protease (serratiopeptidase) from Serratia marcescens e 15. Int Res J Pharm Appl Sci. 2013;3(4):95-8.

13. Grimont F, Grimont PAD. The genus Serratia. Prokaryotes. 2006;6:197-214.

14. Molla A, Matsumoto K, Oyamada I, Katsuki T, Maeda H. Degradation of protease inhibitors, immunoglobulins, and other serum protein by Serratia protease and its toxicity to fibroblasts in culture. Infect Immun. 1986;53(3):522-9.

15. Matsumoto K, Maeda H, Takata K, Kamata R, Okamura R. Purification and characterization of four proteases from a clinical isolate of Serratia marcescens kums 3958. J Bacteriol. 1984;157(1):225-32.
16. Hamada K, Hata Y, Katsuya Y, Hiramatsu H, Fujiwara T, Katsube Y. Crystal structure of Serratia protease, a zinc-dependent proteinase from Serratia sp. $E-15$, containing a $\beta$-sheet coil motif at $2.0 \AA ̊$ resolution. J Biochem. 1996;119(5):844-51.

17. Mahlen SD. Serratia infections: from military experiments to current practice. Clin Microbiol Rev. 2011;24(4):755-91.

18. Petersen LM, Tisa LS. Friend or foe? A review of the mechanisms that drive Serratia towards diverse lifestyles. Can J Microbiol. 2013;59(9):627-40.

19. Kurz C, Chauvet S, Andrès E, Aurouze M, Vallet I, Michel GP, Uh M, Celli J, Filloux A, de Bentzmann S, Steinmetz I, Hoffmann JA, Finlay B, Gorvel J, Ferrandon D, Ewbank JJ. Virulence factors of the human opportunistic pathogen Serratia marcescens identified by in vivo screening. EMBO J. 2003:22(7):1451-60.

20. Lyerly DM, Kreger AS. Importance of serratia protease in the pathogenesis of experimental Serratia marcescens pneumonia. Infect Immun. 1983:40(1):113-9.

21. Kreger AS, Lyerly DM, Hazlett LD, Berk RS. Immunization against experimental Pseudomonas aeruginosa and Serratia marcescens keratitis. Infect Immun. 1986;40(1):932-9.

22. Pansuriya RC, Singhal RS. Evolutionary operation (EVOP) to optimize whey-independent serratiopeptidase production from Serratia marcescens NRRL B-23112. J Microbiol Biotechnol. 2010;20(5):950-7.

23. Taneja K, Bajaj BK, Kumar S, Dilbaghi N. Production, purification and characterization of fibrinolytic enzyme from Serratia sp. KG-2-1 using optimized media. 3 Biotech. 2017;7(3):1-15.

24. Bhagat $S$, Agarwal M, Roy V. Serratiopeptidase: a systematic review of the existing evidence. Int J Surg. 2013;11(3):209-17.

25. Mazzone A, Catalani M, Costanzo M, Drusian A, Mandoli A, Russo S, et al. Evaluation of Serratia peptidase in acute or chronic inflammation of otorhinolaryngology pathology: a multicentre, double-blind randomized trial versus placebo. J Int Med Res. 1990;18(5):379-88.

26. Klein G, Kullich W. Short-term treatment of painful osteoarthritis of the knee with oral enzymes. A randomised, double-blind study versus diclofenac. Clin Drug Investig. 2000;19(1):15-23.

27. Metkar SK, Girigoswami A, Murugesan R, Girigoswami K. In vitro and in vivo insulin amyloid degradation mediated by serratiopeptidase. Mater Sci Eng C. 2017;70:728-35.

28. Selan L, Papa R, Tilotta M, Vrenna G, Carpentieri A, Amoresano A, et al. Serratiopeptidase: a well-known metalloprotease with a new non-proteolytic activity against S. aureus biofilm. BMC Microbiol. 2015;15(1):207.

29. Khanna A, Khanna M, Aggarwal A. Serratia marcescens-a rare opportunistic nosocomial pathogen and measures to limit its spread in hospitalized patients. J Clin Diagn Res. 2013;7(2):243-6.

30. Aucken HM, Pitt TL. Antibiotic resistance and putative virulence factors of Serratia marcescens with respect to $\mathrm{O}$ and $\mathrm{K}$ serotypes. J Med Microbiol. 1998:47(12):1105-13.

31. Richards MJ, Edwards JR, Culver DH, Gaynes RP. Nosocomial infections in combined medical-surgical intensive care units in the United States. Infect Control Hosp Epidemiol. 2010;21(8):510-5.

32. Gastmeier Petra. Serratia marcescens: an outbreak experience. Front Microbiol. 2014;5(81):1-2

33. Rosano GL, Ceccarelli EA. Recombinant protein expression in Escherichia coli: advances and challenges. Front Microbiol. 2014;5(APR):1-17.

34. Tripathi NK, Sathyaseelan K, Jana AM, Rao PVL. High yield production of heterologous protein in Escherichia coli. Def Sci J. 2013;59(2):1-10.

35. Nakahama K, Yoshimura K, Marumoto R, Kikuchi M, Lee IS, Hase T, Matsubara $\mathrm{H}$. Cloning and sequencing of Serratia protease gene. Nucleic Acids Res. 1986;14(14):5843-55.

36. Li AN, Li DC. Cloning, expression and characterization of the serine protease gene from Chaetomium thermophilum. J Appl Microbiol. 2009;106(2):369-80.

37. Kwon K, Hasseman J, Latham S, Grose C, Do Y, Fleischmann RD, et al. Recombinant expression and functional analysis of proteases from Streptococcus pneumoniae, Bacillus anthracis, and Yersinia pestis. BMC Biochem. 2011;12(1):17.

38. Aiyappa PS, Harris JO. The extracellular metalloprotease of Serratia marcescens: I. Purification and characterization. Mol Cell Biochem. 1976;13(2):95-100.

39. Sørensen HP, Mortensen KK. Soluble expression of recombinant proteins in the cytoplasm of Escherichia coli. Microb Cell Fact. 2005;4(1):1-8. 
40. Dumon-Seignovert L, Cariot G, Vuillard L. The toxicity of recombinant proteins in Escherichia coli: a comparison of overexpression in BL21(DE3), C41(DE3), and C43(DE3). Protein Expr Purif. 2004;37(1):203-6.

41. Francis DM, Page R. Strategies to optimize protein expression in E. coli. Curr Protoc Protein Sci. 2010;SUPPL. 61:1-29.

42. Sotomayor-Pérez AC, Ladant D, Chenal A. Calcium-induced folding of intrinsically disordered Repeat-in-Toxin (RTX) motifs via changes of protein charges and oligomerization states. J Biol Chem. 2011:286(19):16997-7004.

43. Mitraki A, Fane B, Haase-petjingell C, Sturtevant J, King J. Global suppression of protein folding defects and inclusion body formation. Science. 1991;253(5015):54-8.

44. Singh A, Upadhyay V, Upadhyay AK, Singh SM, Panda AK. Protein recovery from inclusion bodies of Escherichia coli using mild solubilization process. Microb Cell Fact. 2015;14(1):1-10.

45. Yang Z, Zhang L, Zhang Y, Zhang T, Feng Y, Lu X, et al. Highly efficient production of soluble proteins from insoluble inclusion bodies by a twostep-denaturing and refolding method. PLOS ONE. 2011;6(7):1-8.
46. Shevchenko A, Tomas H, Havliš J, Olsen JV, Mann M. In-gel digestion for mass spectrometric characterization of proteins and proteomes. Nat Protoc. 2007;1(6):2856-60.

47. Kruger NJ. The Bradford method for protein quantitation. In: Walker JM, editor. Basic protein and peptide protocols. Totowa: Humana Press; 1994. p. 9-15.

48. Reichard U, Eiffert H, Rüchel R. Purification and characterization of an extracellular aspartic proteinase from Aspergillus fumigatus. Med Mycol. 1994;32(6):427-36.

\section{Publisher's Note}

Springer Nature remains neutral with regard to jurisdictional claims in published maps and institutional affiliations.
Ready to submit your research? Choose BMC and benefit from:

- fast, convenient online submission

- thorough peer review by experienced researchers in your field

- rapid publication on acceptance

- support for research data, including large and complex data types

- gold Open Access which fosters wider collaboration and increased citations

- maximum visibility for your research: over $100 \mathrm{M}$ website views per year

At BMC, research is always in progress.

Learn more biomedcentral.com/submissions 